\title{
Patients Recovering From Abdominal Surgery Who Walked With Volunteers Exhibited Improved Postoperative Recovery Profiles During Hospitalization
}

\author{
Ugur Cakir · Ertugrul Kargi • Bunyamin Koc
}

Published online: 5 September 2014

(C) Société Internationale de Chirurgie 2014

With great interest, we read the recent article by Le et al. [1] describing the impact of early walking on the mental and physical recovery of postoperative patients. It is admirable that the cited authors considered mental health in this regard. This often is ignored by clinicians assessing postoperative recovery profiles.

Findings clearly show that exercise exerts positive effects on mental health [2] and that behavioral activation is an effective intervention for treating depression [3]. Thus, it is eminently sensible that the cited authors helped patients to walk. However, we were surprised to note that no statistically significant difference was evident between the two reported groups in terms of SF-12 mental composite scores. We expected to see higher scores for the walkers. An explanation may be that the participating ("walking") patients had lower SF-12 mental composite scores than the others before the "walking to recovery" intervention was instituted. We believe that it would be useful to compare the pre- and postoperative mental composite scores of the two groups to illuminate any possible effect of walking on mental health.

U. Cakir $(\square)$

Department of Psychiatry, Abant Izzet Baysal University School of Medicine, Bolu, Turkey

e-mail: ugur_cakir@yahoo.com

E. Kargi

Department of General Surgery, Abant Izzet Baysal University

School of Medicine, Bolu, Turkey

B. Koc

Department of Physical Therapy \& Rehabilitation, Abant Izzet

Baysal University School of Medicine, Bolu, Turkey
In our opinion, future studies assessing postoperative recovery profiles should consider both pre- and postoperative mental scores, readily obtained using specific mental health assessment instruments.

\section{References}

1. Le H, Khankhanian P, Joshi N, Maa J, Crevensten H (2014) Patients recovering from abdominal surgery who walked with volunteers had improved postoperative recovery profiles during their hospitalization. World J Surg 38:1961-1965. doi:10.1007/ s00268-014-2491-5

2. Dunn AL, Trivedi MH, Kampert JB, Clark CG, Chambliss HO (2005) Exercise treatment for depression: efficacy and dose response. Am J Prev Med 28:1-8

3. Dimidjian S, Hollon SD, Dobson KS, Schmaling KB, Kohlenberg RJ, Addis ME, Jacobson NS (2006) Randomized trial of behavioral activation, cognitive therapy, and antidepressant medication in the acute treatment of adults with major depression. J Consult Clin Psychol 74:658-670 